\title{
TNF- $a$ expression ratio of M1/M2 macrophages is a potential adjunctive tool for the diagnosis of autism spectrum disorder
}

\section{Takahira Yamauchi}

Nara Kenritsu Ika Daigaku

Manabu Makinodan ( $\nabla$ mmm@naramed-u.ac.jp )

Nara Kenritsu Ika Daigaku https://orcid.org/0000-0003-4339-9413

Michihiro Toritsuka

Nara Kenritsu Ika Daigaku

Kazuki Okumura

Nara Kenritsu lka Daigaku

Yoshinori Kayashima

Nara Kenritsu Ika Daigaku

Rio Ishida

Nara Kenritsu Ika Daigaku

Naoko Kishimoto

Nara Kenritsu Ika Daigaku

Masato Takahashi

Nara Kenritsu Ika Daigaku

Takashi Komori

Nara Kenritsu Ika Daigaku

Yasunari Yamaguchi

Nara Kenritsu lka Daigaku

Ryohei Takada

Nara Kenritsu Ika Daigaku

Kazuhiko Yamamuro

Nara Kenritsu Ika Daigaku

Sohei Kimoto

Nara Kenritsu Ika Daigaku

Yuka Yasuda

Kokuritsu Seishin Shinkei Center

Ryota Hashimoto

Kokuritsu Seishin Shinkei Center

Toshifumi Kishimoto 


\section{Research}

Keywords: tumor necrosis factor-alpha, autism spectrum disorder, inflammation, macrophage, monocyte, diagnosis

Posted Date: September 9th, 2020

DOI: https://doi.org/10.21203/rs.3.rs-68376/v1

License: (c) (1) This work is licensed under a Creative Commons Attribution 4.0 International License. Read Full License 


\section{Abstract}

Background The etiology of autism spectrum disorder (ASD) is complex. Its pathobiology is characterized by enhanced inflammatory activities; however, the exact ASD pathobiology remains unclear. Some cases of ASD are difficult to diagnose using existing psychological assessments because the careful exclusion of other psychiatric disorders is challenging. To distinguish between the appropriate targets for interventions and research, the demand for identifying efficient diagnostic biomarkers is increasing. This study aimed to find an inflammatory indicator beneficial for the diagnosis of ASD.

Methods Cytokine mRNA expression, including tumor necrosis factor-a (TNF-a), was measured in the differentiated M1 and M2 macrophages of ASD patients $(n=29)$ and typically developed (TD) individuals $(n=30)$. TNF-a expression was also measured in the monocytes of ASD patients $(n=7)$ and TD individuals $(n=6)$.

Results TNF-a expression in M1 macrophages and TNF-a expression ratio of M1/M2 macrophages were markedly higher in ASD patients than in TD subjects; however, this difference was not observed in M2 macrophages (M1: $p<0.01$; ratio of M1/M2: $p<0.0001 ; \mathrm{M} 2: p>0.05$ ), suggesting that this indicator could be a useful tool for diagnosing ASD (M1: sensitivity $=34.5 \%$, specificity $=96.7 \%$, area under the curve $(A U C)=0.74$, positive likelihood ratio $(P L R)=10.34$; ratio of $M 1 / M 2$ : sensitivity $=55.2 \%$, specificity $=96.7 \%, A U C=0.79, P L R=16.55)$. However, there was no significant difference in the TNF-a expression in monocytes between ASD and TD individuals $(p>0.05)$.

Conclusion These findings suggest that TNF-a expression in differentiated macrophages represents a novel adjunctive tool for the diagnosis of ASD.

\section{Introduction}

Autism spectrum disorder (ASD) is a neurodevelopmental disorder characterized by impaired social interaction, poor communication skills, and repetitive or restrictive patterns of behavior and interests (1). The global prevalence of ASD is currently estimated to be 1 in 59 children (2). Although its etiology remains largely unknown and complex, a growing body of evidence implicates the disturbance in the immune system as a mechanism of psychiatric disorders, including ASD (3-5). Alterations in the peripheral innate and adaptive immune responses, as well as prominent inflammation in the brain, have been reported in patients with ASD $(6,7)$. In the periphery, increased expression of pro-inflammatory cytokines, including interleukin-1 beta (IL-1 $\beta$ ), IL-6, tumor necrosis factor alpha (TNF-a), transforming growth factor beta, IL-8, and IL-17 has been observed in the plasma, serum, and peripheral blood mononuclear cells (PBMCs) of patients with $\operatorname{ASD}(7,8)$. Antioxidant networks (e.g., superoxidase dismutase expression and activity) and the responses to innate immunity stimuli (e.g., lipopolysaccharide and zymosan) have been found to be dysregulated in the monocytes of ASD patients (9-11). In the central nervous system (CNS), a positron emission tomography study and a few postmortem studies have shown microglial activation in the brains of ASD patients (12-15). 
Macrophages are myeloid cells that are derived from circulating blood monocytes and are known to behave similarly to microglia (16). These cells play a critical role in immune function and are implicated in the pathology of medical conditions, such as autoimmune and allergic diseases (17-19).

Macrophages can be differentiated into two types: M1 (classically activated macrophages) and M2 (alternatively activated macrophages). Bacterial infection, interferon-y produced by activated T cells, and TNF-a produced by antigen-presenting cells induce the polarization towards M1 macrophages, resulting in phagocytosis and an increase in the release of pro-inflammatory cytokines, such as IL-1 $\beta$, IL-6, and TNF-a (20-22). The uncontrolled production of pro-inflammatory cytokines by M1 macrophages results in the disruption of tissue homeostasis and could increase the risk for neuropsychiatric disorders (2325). In contrast, the polarization towards M2 macrophages is induced by IL-4, IL-10, IL-13, and glucocorticoids and is involved in anti-inflammatory reactions, tissue remodeling, angiogenesis, and tumor progression, with the secretion of growth factors and neurotrophic factors $(26,27)$. M2 macrophages are also implicated in the pathobiology of neuropsychiatric and neurodegenerative disorders, such as bipolar disorder, Parkinson's disease, and multiple sclerosis $(25,28,29)$. Moreover, recent findings have indicated that the polarization of macrophages is a biologically relevant indicator for the evaluation of medical conditions, such as cancer prognosis $(30,31)$.

To date, the diagnosis of ASD has usually relied on a clinical interview using DSM-5, and the most accurate diagnosis is achieved using non-biological tools, namely the Autism Diagnostic Observation Schedule-2 (ADOS-2) and the Autism Diagnostic Interview-Revised (ADI-R) (32, 33). The sensitivity and specificity are $85.9 \%$ and $82.9 \%$ for ADOS-2 and $66.2 \%$ and $89.5 \%$ for ADI-R. When combined, the sensitivity and specificity become $42.2 \%$ and $100 \%$, respectively (34). These tools are highly powerful; however, for more objective assessments, biological diagnostic tools are necessary.

In this study, we aimed to investigate cytokine expression in M1 and M2 macrophages of ASD patients and typically developed (TD) individuals to establish an efficient diagnostic biomarker to aid in the diagnosis of ASD.

\section{Material And Methods}

This study was approved by the ethics committee of Nara Medical University School of Medicine and was carried out in accordance with The Code of Ethics of the World Medical Association (Declaration of Helsinki) for experiments involving humans. All participants were given a complete description of the study and have provided written informed consent before enrollment.

\subsection{Participants And Clinical Assessments}

The participants included 29 ASD patients (age: $28.0 \pm 6.7$ years, 5 females) and 30 TD individuals (age: $27.2 \pm 5.6$ years, 5 females) of Japanese ethnicity. All participants have been born and have been living in Japan. ASD patients were recruited from the outpatient service of the Department of Psychiatry, Nara Medical University Hospital and its affiliated psychiatric clinic. ASD diagnosis was based on the Diagnostic and Statistical Manual of Mental Disorders, Fifth Edition (DSM-5) criteria. At least two 
experienced psychiatrists separately examined the patients, and a diagnostic consensus was reached. Further evaluation was performed using ADOS-2 by psychiatrists and trained staff (35). Autism symptom severity was assessed via self-report using the Autism Quotient-Japanese version (AQ-J)(36, 37). The full intelligence quotient (FIQ) of each participant was estimated using the Similarities and the Symbol search subtests of the Wechsler Adult Intelligence Scale, Third Edition (38). The following exclusion criteria were used: participants under 17 years old; those with low intelligence $(\mathrm{FIQ}<70)$; those diagnosed with other neurological disorders and mental illnesses as evaluated by the Mini-International Neuropsychiatric Interview; and those who used steroids. We did not evaluate Asperger's syndrome.

\subsection{Monocyte Isolation And Macrophage Differentiation}

We used a magnetic-activated cell sorting (MACS) system (Miltenyi Biotec, San Diego, CA, USA) for monocyte isolation, and subsequently we used Human M1 or M2 Macrophage Differentiation Kit (R \& D Systems, Minneapolis, MN, USA) according to the manufacturer's protocol. Briefly, whole human blood samples were collected through venipuncture from all participants during daytime (09:00-16:00) and were stored on ice. Immediately, PBMCs were separated from whole blood using density-gradient centrifugation with the separation medium Lymphoprep (Axis Shield, Oslo, Norway), separation tubes, and Leucosep (Greiner Bio-One, North Carolina, USA). CD14 + monocytes were isolated using the MACS system with CD14 microbeads (Miltenyi Biotec, Bergisch Gladbach, Germany) from PBMCs. These cells were used as monocytes.

For macrophage differentiation, CD14 + monocytes were resuspended in phosphate-buffered saline solution (Wako, Osaka, JAPAN), containing $0.5 \%$ bovine serum albumin (Sigma-Aldrich, St. Louis, MO, USA), 2 mM ethylenediaminetetraacetic acid, and 1\% Penicillin-Streptomycin mixed solution (Nacalai Tesque, Kyoto, JAPAN). They were seeded at a density of $1 \times 10^{6}$ cells $/ \mathrm{mL}$ onto M1 or M2 differentiation medium incubated with the recombinant human granulocyte-macrophage colony-stimulating factor (GM$\mathrm{CSF}$ ) or the recombinant human macrophage colony-stimulating factor (M-CSF), respectively at $37^{\circ} \mathrm{C}$ in a humified atmosphere of $5 \% \mathrm{CO}_{2}$. On day 3 , half of each culture medium was replaced with a fresh medium, and the M1 or M2 macrophages were obtained on day 6.

\subsection{Quantitative RT-PCR (qRT-PCR)}

To measure the mRNA levels of cytokines (i.e., IL-1 $\beta$, IL-6, TNF-a, IL-17RA, and IL-10) and C-C chemokine receptor type 7 (CCR7) in human M1 macrophages, M2 macrophages, and monocytes, total RNA was extracted from the cells using a Direct-Zol RNA miniprep kit (Zymo Research, Irvine, CA) according to the manufacturer's protocol. RNA concentration was determined using the absorbance at $260 \mathrm{~nm}$ measured with a DU 730 spectrophotometer (Beckman Coulter Inc., Fullerton, CA, USA), and the concentration was standardized to be $30 \mathrm{ng} / \mu \mathrm{L}$. First-strand cDNA was synthesized from the total RNA using an iScript kit (Bio-Rad Laboratories, Hercules, CA), and quantitative RT-PCR was performed using SYBR Premix Ex Taq II (Tli RNaseH Plus, TAKARA BIO INC., Otsu, Shiga, Japan) with a StepOne Plus real-time PCR system (Thermo Fisher Scientific Inc.). The normalization and the relative quantification of the expression levels 
of the target genes were performed using the $\triangle \mathrm{CT}$ method, and the constitutively expressed genes $\beta$-actin (ACTB) and cyclophilin A (CyA) were used as internal controls. The mRNA expression ratios of M1/M2 macrophages were calculated by dividing the analyzed gene expression level within M1 macrophages by the same analyzed gene expression level within $M 2$ macrophages. The primer sequences used were as follows: ACTB, forward 5'-GATGTGGATCAGCAAGCA-3', reverse 5'-AGAAAGGGTGTAACGCAACTA-3'; CyA, forward 5'-GCAGACAAGGTCCCAAAG-3', reverse 5'-GAAGTCACCACCCTGACAC-3'; IL-1 $\beta$, forward 5'CTGTCCTGCGTGTTGAAAGA-3', reverse 5'-GAAGACAAATCGCTTTTCCA-3'; IL-6, forward

5'-AGTGAGGAACAAGCCAGAGC-3', reverse 5'-CAGGGGTGGTTATTGCATCT-3'; TNF-a, forward 5'GGCAGTCAGATCATCTTCTCG-3', reverse 5'-CAGCTTGAGGGTTTGCTACA-3'; interleukin 17 receptor A (IL17RA), forward 5'-GTTTTACCTTCAGCCACTTT-3', reverse 5'-ATGGCGTGGTTACCTTCAT-3'; IL-10, forward 5'-GCCTAACATGCTTCGAGATC-3', reverse 5'-TGATGTCTGGGTCTTGGTTC-3'; and CCR7, forward 5'TTCAGTGGCATGCTCCTACTTC-3', reverse 5'-GCTGAGACAGCCTGGACGAT-3'.

\subsection{Statistical Analysis}

Differences between the ASD patients and TD individuals in terms of demographic characteristics, i.e., age, educational level, and FIQ, were examined using Welch's $t$-test, and Fisher's exact test was used to examine the differences in sex and allergic diseases. qRT-PCR data are presented as median values and interquartile ranges. Comparisons were performed using the Mann-Whitney Utest. RNA concentration data were presented as the mean and standard error of the mean. The comparison was performed using one-way analysis of variance. Positive likelihood ratios (PLRs) were used to evaluate the ability of cytokine expression in M1 and M2 macrophages in predicting ASD diagnosis. The PLR is one of the best methods to evaluate diagnostic accuracy and gives the change in the odds of having a diagnosis in patients with a positive test (39). A PLR of 10 indicates a 10-fold increase in the odds of a particular condition in a patient with a positive test result. Normally, PLRs of greater than 10 significantly increase the probability of a disease (40). The PLR is calculated as sensitivity/(1- specificity) through the receiver operating characteristic (ROC) curves. Correlation analyses between gene expression levels and age, FIQ, and the severity of ASD symptoms were performed using Spearman's rank correlation. Logistic regression analysis was used to examine the association between TNF- $a$ mRNA expression in macrophages and the prevalence of allergic diseases. All statistical analyses were performed using Prism 8 (GraphPad), except for logistic regression analysis, which was performed using SPSS version 26 (IBM). $P$-values $<0.05$ were considered statistically significant and are indicated in the figures as ${ }^{\star} p<0.05,{ }^{\star} p<0.01,{ }^{\star} * \star p<0.001$,

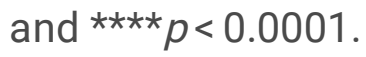

\section{Results}

Table 1 presents the demographic data of the participants in this study. There were no significant differences in age $(U=403, p=0.63)$ or $\operatorname{sex}\left(\chi^{2}[1]=0.003, p=1.00\right)$ between the ASD and TD groups. ASD patients showed significantly lower educational level $(U=213.5, p=0.0004)$ and lower FIQ $(U=233.5, p=$ 0.0019) compared with TD individuals. The prevalence of allergic diseases was higher in ASD patients 
than in TD participants $\left(\chi^{2}[1]=5.77, p=0.02\right)$. Allergic diseases included asthma, atopic dermatitis, and food allergies.

\subsection{Cytokine expression in M1 and M2 macrophages: differences between ASD patients and TD participants}

Prior to the measurement of the mRNA expression levels of cytokines, we have confirmed that the total RNA concentrations of harvested M1 and M2 macrophages were not different between ASD and TD groups (Suppl. Figure 1). This suggests no difference in the number of differentiated M1 and M2 macrophage cells between the two groups. Then, we measured the mRNA expression levels of CCR7 and IL-10 as markers for M1 and M2 macrophages, respectively $(41,42)$. The mRNA expression level of CCR7 was higher in $\mathrm{M} 1$ than in $\mathrm{M} 2$ macrophages $(U=27, p=0.0079)$, whereas that of $I L-10$ was higher in $\mathrm{M} 2$ than in $\mathrm{M} 1$ macrophages $(U=0, p<0.0001)$, thus confirming the differentiation into M1 and M2 macrophages (Suppl. Figure 2).

Next, the mRNA expression levels of pro-inflammatory cytokines (IL-1 $\beta$, IL-6, TNF-a, and IL-17RA) and that of an anti-inflammatory cytokine (IL-10) were measured in M1 and M2 macrophages. Increased expression of $I L-1 \beta$ and TNF- $a$ mRNA in M1 macrophages, but not in M2 macrophages, were observed in ASD patients compared with TD individuals (M1: TNF- $a, p=0.0011, \mathrm{r}=0.42, I L-1 \beta, p=0.049, \mathrm{r}=0.26$; $\mathrm{M} 2$ : TNF- $a, p=0.64, I L-1 \beta, p=0.42$ ) (Fig. $1 \mathrm{~A}, \mathrm{~B}$ ). The expression levels of $I L-6$ and $I L-10$ in $M 1$ and $M 2$ macrophages did not differ between the two groups (M1: $I L-6, p=0.42 ; I L-10, p=0.21 ; M 2: I L-6, p=0.27$, IL-10, $p=0.25)$ (Fig. 1C, D).

Because a previous study has revealed the abnormal expression of IL-17A and IL-17RA in ASD patients $(43,44)$, we also examined the mRNA expression level of $I L-17 R A$, but found no significant difference in $\mathrm{M} 1$ or $\mathrm{M} 2$ macrophages between the two groups (M1: IL-17RA, $p=0.42$; M2: IL-17RA, $p=0.45$ ) (Fig. 1E). From the calculated mRNA expression ratios of M1/M2 macrophages, which may indicate the pattern of inflammatory responses of these macrophages, we found that only that of TNF-a was markedly higher in ASD patients than in TD individuals (M1/M2: TNF- $a, p<0.0001, r=0.50$ ) (Fig. 1A). Importantly, logistic regression analysis revealed no associations between the TNF- $a$ expression in M1, M2, and M1/M2 macrophages and prevalence of allergic diseases (Suppl. Table 1). 
Table 1. Basic characteristics and clinical parameters

\begin{tabular}{lccc}
\hline \multicolumn{1}{c}{ characteristics } & $\begin{array}{c}\text { TD } \\
(\mathrm{n}=30)\end{array}$ & $\begin{array}{c}\text { ASD } \\
(\mathrm{n}=29)\end{array}$ & p-value \\
\hline Age: mean (SD) & $27.2(5.6)$ & $28.0(6.9)$ & 0.63 \\
Sex: male, $\mathrm{n}(\%)$ & $25(83.3)$ & $24(82.8)$ & 1.00 \\
Education period: median (IQR) & $16.0(15.8-18.0)$ & $13.0(12.0-16.0)$ & $0.0004^{\star * *}$ \\
Full-scale IQ: mean (SD) & $106.0(11.7)$ & $94.8(13.3)$ & $0.0019^{* *}$ \\
Allergic disease, $\mathrm{n}(\%)$ & $2(6.7)$ & $9(31.0)$ & $0.021^{*}$ \\
AQ-J score: mean (SD) & $21.2(6.5)$ & $33.5(5.1)$ & $<0.0001^{\star * \star *}$ \\
\hline
\end{tabular}

Allergic disease includes atopic dermatitis, asthma and food allergies.

$I Q$, intelligence quotient.

AQ-J, Autism-Spectrum Quotient Japanease version.

$\mathrm{SD}$, standard deviation. IQR, interquartile range.

TD, typically developing. ASD, autism spectrum disorder.

\subsection{TNF-a mRNA expression ratio of M1/M2 macrophages as a potential biomarker for ASD}

The ROC curves of cytokine expression in M1 and M2 macrophages, as well as the expression ratios of M1/M2 macrophages, were delineated to calculate the sensitivity, specificity, and PLR (Table 2). The AUCs of TNF- $a$ mRNA expression in M1 macrophages and its expression ratio of M1/M2 macrophages were significantly higher than the chance level (Fig. 2A-C) (Suppl. Figure 3A-D). PLR was calculated to validate the usefulness of cytokine expression for ASD diagnosis. The PLR of mRNA expression ratio of TNF-a of M1/M2 macrophages was calculated as 16.55 (sensitivity: 55.2\%, specificity: 96.7\%) (Fig. 2C). These findings overall suggest that the diagnostic accuracy of ASD can be remarkably improved with the reduction of false positives by the addition of TNF- $a$ mRNA expression ratio of M1/M2 macrophages to psychiatrists' examination.

Table 2. Sensitivity, Specificity, and Positive Likelihood Ratio of TNF-a expression for ASD diagnosis

\begin{tabular}{lcccc}
\hline & Positive Predictive Value & $\begin{array}{c}\text { Sensitivity\% } \\
(95 \% \mathrm{Cl})\end{array}$ & $\begin{array}{c}\text { Specificity\% } \\
(95 \% \mathrm{Cl})\end{array}$ & Positive Likelihood Ratio \\
\hline TNF- $\alpha$ M1 & \multirow{2}{*}{1.836} & 34.5 & 96.7 & 10.34 \\
TNF- $\alpha$ M2 & \multirow{2}{*}{0.268} & $19.9-52.7)$ & $(83.3-99.8)$ & 3.10 \\
TNF- $\alpha$ M1/M2 & \multirow{2}{*}{1.853} & $(3.6-26.4)$ & $(83.3-99.8)$ & 16.55 \\
\hline
\end{tabular}

\subsection{No correlations between TNF-a mRNA expression ratio of M1/M2 macrophages and age, FIQ, and the severity of ASD symptoms.}

TNF- $a$ mRNA expression in either M1 or M2 macrophages did not correlate with age, FIQ, or the severity of ASD symptoms (AQ-J score) in ASD and TD except for the correlation of TNF- $a$ mRNA expression in M2 macrophages with AQ-J score. TNF- $a$ mRNA expression ratios in M1/M2 macrophages did not correlate 
with either the age, FIQ, or AQ-J score in ASD and TD (Fig. 2D), suggesting that this biomarker can be used to evaluate a broad range of ASD patients.

\subsection{TNF-a mRNA expression in monocytes between ASD patients and TD participants}

Moreover, the monocytes in participants with further informed consent were collected, and their TNF-a mRNA expression level was measured to validate the necessity of macrophage differentiation. We found no significant difference in TNF- $a$ mRNA expression between ASD patients and TD individuals $(U=15, p$ $=0.45$ ) (Fig. 3). In contrast, TNF- $a$ mRNA expression in M1 macrophages and TNF- $a$ mRNA expression ratios in M1/M2 macrophages were significantly different between ASD patients and TD individuals (M1: $U=4, p=0.01 ; \mathrm{M} 1 / \mathrm{M} 2: U=0, p=0.001)$, suggesting the value of macrophages for the determination of ASD endophenotypes.

\section{Discussion}

ASD diagnosis is often based on psychological assessments, including ADOS-2 and ADI-R, which are time-consuming and relatively subjective $(35,45)$. Therefore, more objective indicators, such as biomarkers, are required for more accurate ASD diagnosis. In this study, we have provided evidence indicating the potential of the TNF-a mRNA expression ratio of M1/M2 macrophages with high sensitivity to increase the rate of true positive ASD diagnosis.

Although there have been several reports on the potential of monocytes as biomarkers for ASD diagnosis $(11,43,46)$, to the best of our knowledge, there are no studies investigating $M 1$ and $M 2$ macrophages. We have induced the polarization of circulating blood monocytes into both $\mathrm{M} 1$ and $\mathrm{M} 2$ macrophages in vitro and have measured their cytokine expression levels. A series of transcription factors and posttranscriptional regulators play a critical role in $\mathrm{M} 1$ and $\mathrm{M} 2$ polarization (26), which controls immune responses by balancing inflammation-related cytokines; pro-inflammatory cytokines such as TNF-a were predominantly expressed in M1 macrophage, and anti-inflammatory cytokines such as IL-10 were predominantly expressed in M2 macrophages (47). In this study, the expression levels of IL-10 were not different in either M1 or M2 macrophages between ASD patients and TD individuals. In contrast, TNF-a expression was substantially increased in M1 but not M2 macrophages in ASD patients compared to TD individuals, indicating that, at least, the balance of TNF-a and IL-10 expression in macrophages and that of TNF-a expression in M1 and M2 macrophages tilted towards inflammation in ASD patients.

TNF-a is a pleiotropic cytokine regulating brain development and function $(48,49)$. It has been shown that TNF-a is associated with the pathobiology of schizophrenia, bipolar disorder, major depressive disorder, and ASD (50-52). An increase in serum TNF-a expression has also been shown in ASD patients from childhood through adulthood $(53,54)$, which is consistent with the current finding that there were no correlations between age and TNF- $a$ mRNA expression levels (Fig. 2D). While TNF- $a$ is expressed in multiple cell types, such as monocytes, T cells, mast cells, NK cells, keratinocytes, fibroblasts, and neurons, it is predominantly produced by the macrophages and microglia $(55,56)$. Glial TNF-a regulates homeostatic activity-dependent synaptic connectivity, which plays a critical role in the developing brain 
$(57,58)$. TNF-a derived from microglia is also known to modulate neuronal functions temporally $(59)$. However, brain region-specificity of the effect of TNF-a, the chronicity, and its relevance to ASD symptoms in humans remain unclear. Furthermore, TNF- $a$ has been generally accepted to be too large to cross the brain-blood barrier (BBB), which prevents macrophage infiltration in the brain (60). Nevertheless, TNF-a permeability varies depending on brain regions, i.e., its permeability is higher in the hypothalamus than in the parietal cortex (61). Transporters also help TNF-a to gain access into the brain (62), indicating that macrophage-derived TNF-a could affect brain functions under certain conditions. The breach of the BBB by TNF-a may lead to increased entry of blood macrophages into the brain (63). Furthermore, recent findings indicate that perivascular macrophages-regularly renewed by monocytes-may be critical players in controlling brain functions (64). Thus, macrophage-derived TNF-a is likely to regulate brain functions and may contribute to the development of neuropsychiatric disorders, as is the case with microglia-derived TNF-a.

TNF-a has also been known to cause autoimmune diseases, such as rheumatoid arthritis (RA). TNF-a inhibitors, such as infliximab, etanercept, adalimumab, golimumab, and certolizumab pegol, have been prescribed for RA treatment (65). An increased number of macrophages are found in the synovial tissue. Macrophages produce TNF-a, and the number of macrophages significantly correlates with the degree of joint erosion and the change in the disease-activity score $(66,67)$. Moreover, the M1 or M2 macrophage phenotypes in the synovial fluid depend on the disease phase (68). It is, however, of note that no previous studies have shown a difference in TNF-a expression in either circulating blood monocytes or monocytederived macrophages between RA patients and controls. This difference, if found to exist, would indicate that macrophages in the synovial tissue differ from those derived from monocytes and are therefore specific to RA pathology (69).

TNF-a has also been implicated in the pathobiology of allergic diseases such as atopic dermatitis. While it has been shown that a single-gene polymorphism of TNF-a is significantly associated with the diagnosis of atopic dermatitis (70), and that TNF-a expression in the serum is elevated in patients with atopic dermatitis compared with the controls (71), no previous studies have shown the alterations in TNFa expression in blood-circulating monocytes or monocyte-derived macrophages in these patients. We have found that ASD patients tend to suffer from allergic diseases, but not autoimmune diseases, including RA, compared with TD individuals (Table 1). Notably, we did not find any correlation between the prevalence of allergic diseases and TNF-a expression levels (Suppl. Table 1), indicating that the aberrant expression of TNF-a in monocyte-derived macrophages is likely due to ASD, not allergic diseases.

Considering that TNF-a has been implicated in social stress-induced behaviors (72), the potential of our proposed tool for diagnosing other psychiatric disorders, such as depression, remains to be investigated. This diagnostic tool might be useful for the identification of more moderate ASD cases, which are rather difficult to diagnose because TNF-a mRNA expression levels did not correlate with either FIQ or the severity of ASD symptoms based on AQ-J scores (Fig. 2D). Another limitation in our study is the small number of participants; therefore, the effect of sex difference could not be determined. Further, ASD 
patients had lower full-scale IQ scores and fewer years of education than TD individuals. Lastly, because all participants were Japanese, future studies to assess the generalizability of our findings to a more diverse population are needed.

\section{Conclusion}

Our findings have revealed that the TNF- $a$ expression ratio of M1/M2 macrophages improves diagnostic specificity up to $96.7 \%$, AUC up to 0.79 , and PLR up to 16.55 , thus providing a valuable biological tool to aid in the diagnosis of ASD.

\section{List Of Abbreviations}

Autism spectrum disorder (ASD)

Interleukin (IL)

tumor necrosis factor alpha (TNF-a)

peripheral blood mononuclear cells (PBMCs)

central nervous system (CNS)

Autism Diagnostic Observation Schedule-2 (ADOS-2)

Autism Diagnostic Interview-Revised (ADI-R)

typically developed (TD)

Diagnostic and Statistical Manual of Mental Disorders, Fifth Edition (DSM-5)

full-intelligence quotient (FIQ)

magnetic-activated cell sorting (MACS)

$\beta$-actin (ACTB)

cyclophilin A (CyA)

interleukin 17 receptor A (IL-17RA)

Positive likelihood ratios (PLRs)

receiver operating characteristic (ROC)

brain blood barrier (BBB) 


\section{Declarations}

\section{Ethics approval and consent to participate}

This study was approved by the ethics committee of Nara Medical University School of Medicine and was carried out in accordance with The Code of Ethics of the World Medical Association (Declaration of Helsinki) for experiments involving humans. All participants were given a complete description of the study and have provided their written informed consent before enrollment.

\section{Consent for publication}

$\mathrm{N} / \mathrm{A}$

\section{Availability of data and materials}

The datasets used and/or analyzed during the current study are available from the corresponding author upon reasonable request.

\section{Competing interests}

The authors declare that they have no competing interests.

\section{Funding}

This work was supported by the Japan Society for the Promotion of Science Grants-in-Aid for Scientific Research Program (grant numbers: JP25861024, JP16K19779, JP16H06403, JP16H05377, JP17K10339, and JP18K07609]; the Takeda Science Foundation; the Naito Foundation, and the Grants-in-Aid from Nara Medical University.

\section{Authors' contributions}

TY, MM, and TK wrote the manuscript. TY, MM, MT, KO, YK, TK, YY, RY, KY, and SK performed the molecular biology and cell biology experiments. RI, NK, MT, YY, and RH performed ADOS-2.

\section{Acknowledgements}

We are grateful for the cooperation and patience of participants who made this work possible.

\section{References}

1. Gyawali S, Patra BN. Autism spectrum disorder: Trends in research exploring etiopathogenesis. Psychiatry and clinical neurosciences. 2019 Aug;73(8):466-75. PubMed PMID: 31077508. 
2. Baio J, Wiggins L, Christensen DL, Maenner MJ, Daniels J, Warren Z, et al. Prevalence of Autism Spectrum Disorder Among Children Aged 8 Years - Autism and Developmental Disabilities Monitoring Network, 11 Sites, United States, 2014. Morbidity and mortality weekly report Surveillance summaries. 2018 Apr 27;67(6):1-23. PubMed PMID: 29701730. Pubmed Central PMCID: 5919599.

3. Khandaker GM, Cousins L, Deakin J, Lennox BR, Yolken R, Jones PB. Inflammation and immunity in schizophrenia: implications for pathophysiology and treatment. The lancet Psychiatry. 2015 Mar;2(3):258-70. PubMed PMID: 26359903. Pubmed Central PMCID: 4595998.

4. Pape K, Tamouza R, Leboyer M, Zipp F. Immunoneuropsychiatry - novel perspectives on brain disorders. Nature reviews Neurology. 2019 Jun;15(6):317-28. PubMed PMID: 30988501.

5. Furuyashiki T, Kitaoka S. Neural mechanisms underlying adaptive and maladaptive consequences of stress: Roles of dopaminergic and inflammatory responses. Psychiatry and clinical neurosciences. 2019 Nov;73(11):669-75. PubMed PMID: 31215710.

6. Hughes HK, Mills Ko E, Rose D, Ashwood P. Immune Dysfunction and Autoimmunity as Pathological Mechanisms in Autism Spectrum Disorders. Frontiers in cellular neuroscience. 2018;12:405. PubMed PMID: 30483058. Pubmed Central PMCID: 6242891.

7. Matta SM, Hill-Yardin EL, Crack PJ. The influence of neuroinflammation in Autism Spectrum Disorder. Brain, behavior, and immunity. 2019 Jul;79:75-90. PubMed PMID: 31029798.

8. Masi A, Quintana DS, Glozier N, Lloyd AR, Hickie IB, Guastella AJ. Cytokine aberrations in autism spectrum disorder: a systematic review and meta-analysis. Molecular psychiatry. 2015 Apr;20(4):4406. PubMed PMID: 24934179.

9. Jyonouchi H, Geng L, Streck DL, Dermody JJ, Toruner GA. MicroRNA expression changes in association with changes in interleukin-1ss/interleukin10 ratios produced by monocytes in autism spectrum disorders: their association with neuropsychiatric symptoms and comorbid conditions (observational study). Journal of neuroinflammation. 2017 Nov 25;14(1):229. PubMed PMID: 29178897. Pubmed Central PMCID: 5702092.

10. Jyonouchi H, Geng L. Associations between Monocyte and T Cell Cytokine Profiles in Autism Spectrum Disorders: Effects of Dysregulated Innate Immune Responses on Adaptive Responses to Recall Antigens in a Subset of ASD Children. International journal of molecular sciences. 2019 Sep 24;20(19). PubMed PMID: 31554204. Pubmed Central PMCID: 6801811.

11. Nadeem A, Ahmad SF, Attia SM, Al-Ayadhi LY, Al-Harbi NO, Bakheet SA. Dysregulated enzymatic antioxidant network in peripheral neutrophils and monocytes in children with autism. Progress in neuro-psychopharmacology \& biological psychiatry. 2019 Jan 10;88:352-9. PubMed PMID: 30145184.

12. Suzuki K, Sugihara G, Ouchi Y, Nakamura K, Futatsubashi M, Takebayashi K, et al. Microglial activation in young adults with autism spectrum disorder. JAMA psychiatry. 2013 Jan;70(1):49-58. PubMed PMID: 23404112. Epub 2013/02/14. eng.

13. Lee AS, Azmitia EC, Whitaker-Azmitia PM. Developmental microglial priming in postmortem autism spectrum disorder temporal cortex. Brain, behavior, and immunity. 2017 May;62:193-202. PubMed 
PMID: 28159644.

14. Velmeshev D, Schirmer L, Jung D, Haeussler M, Perez Y, Mayer S, et al. Single-cell genomics identifies cell type-specific molecular changes in autism. Science. 2019 May 17;364(6441):685-9. PubMed PMID: 31097668.

15. Morgan JT, Chana G, Pardo CA, Achim C, Semendeferi K, Buckwalter J, et al. Microglial activation and increased microglial density observed in the dorsolateral prefrontal cortex in autism. Biological psychiatry. 2010 Aug 15;68(4):368-76. PubMed PMID: 20674603. Epub 2010/08/03. eng.

16. Ohgidani M, Kato TA, Setoyama D, Sagata N, Hashimoto R, Shigenobu K, et al. Direct induction of ramified microglia-like cells from human monocytes: Dynamic microglial dysfunction in NasuHakola disease. Scientific reports. 2014;4:4957. PubMed PMID: 24825127. Pubmed Central PMCID: 4019954.

17. Gordon S, Taylor PR. Monocyte and macrophage heterogeneity. Nature reviews Immunology. 2005 Dec;5(12):953-64. PubMed PMID: 16322748.

18. Siouti E, Andreakos E. The many facets of macrophages in rheumatoid arthritis. Biochemical pharmacology. 2019 Jul;165:152-69. PubMed PMID: 30910693.

19. Beck LA, Leung DY. Allergen sensitization through the skin induces systemic allergic responses. The Journal of allergy and clinical immunology. 2000 Nov;106(5 Suppl):S258-63. PubMed PMID: 11080741.

20. Liu YC, Zou XB, Chai YF, Yao YM. Macrophage polarization in inflammatory diseases. International journal of biological sciences. 2014;10(5):520-9. PubMed PMID: 24910531. Pubmed Central PMCID: 4046879.

21. Benoit M, Desnues B, Mege JL. Macrophage polarization in bacterial infections. Journal of immunology. 2008 Sep 15;181(6):3733-9. PubMed PMID: 18768823.

22. Martinez FO, Gordon S. The M1 and M2 paradigm of macrophage activation: time for reassessment. F1000prime reports. 2014;6:13. PubMed PMID: 24669294. Pubmed Central PMCID: 3944738.

23. Dey A, Hankey Giblin PA. Insights into Macrophage Heterogeneity and Cytokine-Induced Neuroinflammation in Major Depressive Disorder. Pharmaceuticals. 2018 Jun 25;11(3). PubMed PMID: 29941796. Pubmed Central PMCID: 6160985.

24. Siniscalco D, Schultz S, Brigida AL, Antonucci N. Inflammation and Neuro-Immune Dysregulations in Autism Spectrum Disorders. Pharmaceuticals. 2018 Jun 4;11(2). PubMed PMID: 29867038. Pubmed Central PMCID: 6027314.

25. Moehle MS, West AB. M1 and M2 immune activation in Parkinson's Disease: Foe and ally? Neuroscience. 2015 Aug 27;302:59-73. PubMed PMID: 25463515. Pubmed Central PMCID: 4442748.

26. Sica A, Mantovani A. Macrophage plasticity and polarization: in vivo veritas. The Journal of clinical investigation. 2012 Mar;122(3):787-95. PubMed PMID: 22378047. Pubmed Central PMCID: 3287223.

27. Michell-Robinson MA, Touil H, Healy LM, Owen DR, Durafourt BA, Bar-Or A, et al. Roles of microglia in brain development, tissue maintenance and repair. Brain : a journal of neurology. $2015 \mathrm{May} ; 138(\mathrm{Pt}$ 5):1138-59. PubMed PMID: 25823474. Pubmed Central PMCID: 5963417. 
28. Ascoli BM, Parisi MM, Bristot G, Antqueviezc B, Gea LP, Colombo R, et al. Attenuated inflammatory response of monocyte-derived macrophage from patients with $\mathrm{BD}$ : a preliminary report. International journal of bipolar disorders. 2019 Jun 1;7(1):13. PubMed PMID: 31152269. Pubmed Central PMCID: 6544740.

29. Chu F, Shi M, Zheng C, Shen D, Zhu J, Zheng X, et al. The roles of macrophages and microglia in multiple sclerosis and experimental autoimmune encephalomyelitis. Journal of neuroimmunology. 2018 May 15;318:1-7. PubMed PMID: 29606295.

30. Cui YL, Li HK, Zhou HY, Zhang T, Li Q. Correlations of tumor-associated macrophage subtypes with liver metastases of colorectal cancer. Asian Pacific journal of cancer prevention : APJCP. 2013;14(2):1003-7. PubMed PMID: 23621176.

31. Pantano F, Berti P, Guida FM, Perrone G, Vincenzi B, Amato MM, et al. The role of macrophages polarization in predicting prognosis of radically resected gastric cancer patients. Journal of cellular and molecular medicine. 2013 Nov;17(11):1415-21. PubMed PMID: 24283947. Pubmed Central PMCID: 4117554.

32. Falkmer T, Anderson K, Falkmer M, Horlin C. Diagnostic procedures in autism spectrum disorders: a systematic literature review. European child \& adolescent psychiatry. 2013 Jun;22(6):329-40. PubMed PMID: 23322184.

33. Ozonoff S, Goodlin-Jones BL, Solomon M. Evidence-based assessment of autism spectrum disorders in children and adolescents. Journal of clinical child and adolescent psychology : the official journal for the Society of Clinical Child and Adolescent Psychology, American Psychological Association, Division 53. 2005 Sep;34(3):523-40. PubMed PMID: 16083393.

34. Fusar-Poli L, Brondino N, Rocchetti M, Panisi C, Provenzani U, Damiani S, et al. Diagnosing ASD in Adults Without ID: Accuracy of the ADOS-2 and the ADI-R. Journal of autism and developmental disorders. 2017 Nov;47(11):3370-9. PubMed PMID: 28755032.

35. Lord C, Rutter M, Goode S, Heemsbergen J, Jordan H, Mawhood L, et al. Autism diagnostic observation schedule: a standardized observation of communicative and social behavior. Journal of autism and developmental disorders. 1989 Jun;19(2):185-212. PubMed PMID: 2745388.

36. Baron-Cohen S, Wheelwright S, Skinner R, Martin J, Clubley E. The autism-spectrum quotient (AQ): evidence from Asperger syndrome/high-functioning autism, males and females, scientists and mathematicians. Journal of autism and developmental disorders. 2001 Feb;31(1):5-17. PubMed PMID: 11439754.

37. Kurita H, Koyama T, Osada H. Autism-Spectrum Quotient-Japanese version and its short forms for screening normally intelligent persons with pervasive developmental disorders. Psychiatry and clinical neurosciences. 2005 Aug;59(4):490-6. PubMed PMID: 16048456.

38. Sumiyoshi C, Fujino H, Sumiyoshi T, Yasuda Y, Yamamori H, Ohi K, et al. Usefulness of the Wechsler Intelligence Scale short form for assessing functional outcomes in patients with schizophrenia. Psychiatry research. 2016 Nov 30;245:371-8. PubMed PMID: 27591412. 
39. McGee S. Simplifying likelihood ratios. Journal of general internal medicine. 2002 Aug;17(8):646-9. PubMed PMID: 12213147. Pubmed Central PMCID: 1495095.

40. Akobeng AK. Understanding diagnostic tests 2: likelihood ratios, pre- and post-test probabilities and their use in clinical practice. Acta paediatrica. 2007 Apr;96(4):487-91. PubMed PMID: 17306009.

41. Wang ZC, Yao Y, Wang N, Liu JX, Ma J, Chen CL, et al. Deficiency in interleukin-10 production by M2 macrophages in eosinophilic chronic rhinosinusitis with nasal polyps. International forum of allergy \& rhinology. 2018 Nov;8(11):1323-33. PubMed PMID: 30281939.

42. Xuan W, Qu Q, Zheng B, Xiong S, Fan GH. The chemotaxis of M1 and M2 macrophages is regulated by different chemokines. Journal of leukocyte biology. 2015 Jan;97(1):61-9. PubMed PMID: 25359998.

43. Nadeem A, Ahmad SF, Attia SM, Bakheet SA, Al-Harbi NO, Al-Ayadhi LY. Activation of IL-17 receptor leads to increased oxidative inflammation in peripheral monocytes of autistic children. Brain, behavior, and immunity. 2018 Jan;67:335-44. PubMed PMID: 28935156.

44. Akintunde ME, Rose M, Krakowiak P, Heuer L, Ashwood P, Hansen R, et al. Increased production of IL17 in children with autism spectrum disorders and co-morbid asthma. Journal of neuroimmunology. 2015 Sep 15;286:33-41. PubMed PMID: 26298322. Pubmed Central PMCID: 4548834.

45. Lord C, Rutter M, Le Couteur A. Autism Diagnostic Interview-Revised: a revised version of a diagnostic interview for caregivers of individuals with possible pervasive developmental disorders. Journal of autism and developmental disorders. 1994 Oct;24(5):659-85. PubMed PMID: 7814313.

46. Nadeem A, Ahmad SF, Al-Ayadhi LY, Attia SM, Al-Harbi NO, Alzahrani KS, et al. Differential regulation of Nrf2 is linked to elevated inflammation and nitrative stress in monocytes of children with autism. Psychoneuroendocrinology. 2019 Dec 23;113:104554. PubMed PMID: 31884317.

47. Atri C, Guerfali FZ, Laouini D. Role of Human Macrophage Polarization in Inflammation during Infectious Diseases. International journal of molecular sciences. 2018 Jun 19;19(6). PubMed PMID: 29921749. Pubmed Central PMCID: 6032107.

48. Babri S, Doosti MH, Salari AA. Tumor necrosis factor-alpha during neonatal brain development affects anxiety- and depression-related behaviors in adult male and female mice. Behavioural brain research. 2014 Mar 15;261:305-14. PubMed PMID: 24398264.

49. McCoy MK, Tansey MG. TNF signaling inhibition in the CNS: implications for normal brain function and neurodegenerative disease. Journal of neuroinflammation. 2008 Oct 17;5:45. PubMed PMID: 18925972. Pubmed Central PMCID: 2577641.

50. Hoseth EZ, Ueland T, Dieset I, Birnbaum R, Shin JH, Kleinman JE, et al. A Study of TNF Pathway Activation in Schizophrenia and Bipolar Disorder in Plasma and Brain Tissue. Schizophrenia bulletin. 2017 Jul 1;43(4):881-90. PubMed PMID: 28049760. Pubmed Central PMCID: 5515106.

51. Xie J, Huang L, Li X, Li H, Zhou Y, Zhu H, et al. Immunological cytokine profiling identifies TNF-alpha as a key molecule dysregulated in autistic children. Oncotarget. 2017 Oct 10;8(47):82390-8. PubMed PMID: 29137272. Pubmed Central PMCID: 5669898. 
52. Zhou R, Wang F, Zhao G, Xia W, Peng D, Mao R, et al. Effects of tumor necrosis factor-alpha polymorphism on the brain structural changes of the patients with major depressive disorder. Translational psychiatry. 2018 Oct 11;8(1):217. PubMed PMID: 30310056. Pubmed Central PMCID: 6181976.

53. Ghaffari MA, Mousavinejad E, Riahi F, Mousavinejad M, Afsharmanesh MR. Increased Serum Levels of Tumor Necrosis Factor-Alpha, Resistin, and Visfatin in the Children with Autism Spectrum Disorders: A Case-Control Study. Neurology research international. 2016;2016:9060751. PubMed PMID: 28018676. Pubmed Central PMCID: 5149679.

54. Ricci S, Businaro R, Ippoliti F, Lo Vasco VR, Massoni F, Onofri E, et al. Altered cytokine and BDNF levels in autism spectrum disorder. Neurotoxicity research. 2013 Nov;24(4):491-501. PubMed PMID: 23604965.

55. Tracey D, Klareskog L, Sasso EH, Salfeld JG, Tak PP. Tumor necrosis factor antagonist mechanisms of action: a comprehensive review. Pharmacology \& therapeutics. 2008 Feb;117(2):244-79. PubMed PMID: 18155297.

56. Gregersen R, Lambertsen K, Finsen B. Microglia and macrophages are the major source of tumor necrosis factor in permanent middle cerebral artery occlusion in mice. Journal of cerebral blood flow and metabolism : official journal of the International Society of Cerebral Blood Flow and Metabolism. 2000 Jan;20(1):53-65. PubMed PMID: 10616793.

57. Kim YS, Joh TH. Microglia, major player in the brain inflammation: their roles in the pathogenesis of Parkinson's disease. Experimental \& molecular medicine. 2006 Aug 31;38(4):333-47. PubMed PMID: 16953112.

58. Stellwagen D, Malenka RC. Synaptic scaling mediated by glial TNF-alpha. Nature. 2006 Apr 20;440(7087):1054-9. PubMed PMID: 16547515.

59. Yamamoto M, Kim M, Imai H, Itakura Y, Ohtsuki G. Microglia-Triggered Plasticity of Intrinsic Excitability Modulates Psychomotor Behaviors in Acute Cerebellar Inflammation. Cell reports. 2019 Sep 10;28(11):2923-38 e8. PubMed PMID: 31509752.

60. Stranahan AM, Hao S, Dey A, Yu X, Baban B. Blood-brain barrier breakdown promotes macrophage infiltration and cognitive impairment in leptin receptor-deficient mice. Journal of cerebral blood flow and metabolism : official journal of the International Society of Cerebral Blood Flow and Metabolism. 2016 Dec;36(12):2108-21. PubMed PMID: 27034250. Pubmed Central PMCID: 5363667.

61. Avino TA, Hutsler JJ. Abnormal cell patterning at the cortical gray-white matter boundary in autism spectrum disorders. Brain research. 2010 Nov 11;1360:138-46. PubMed PMID: 20816758.

62. Banks WA. Blood-brain barrier transport of cytokines: a mechanism for neuropathology. Current pharmaceutical design. 2005;11(8):973-84. PubMed PMID: 15777248.

63. Cheng Y, Desse S, Martinez A, Worthen RJ, Jope RS, Beurel E. TNFalpha disrupts blood brain barrier integrity to maintain prolonged depressive-like behavior in mice. Brain, behavior, and immunity. 2018 Mar;69:556-67. PubMed PMID: 29452218. Pubmed Central PMCID: 5963697. 
64. McKim DB, Weber MD, Niraula A, Sawicki CM, Liu X, Jarrett BL, et al. Microglial recruitment of IL1 beta-producing monocytes to brain endothelium causes stress-induced anxiety. Molecular psychiatry. 2018 Jun;23(6):1421-31. PubMed PMID: 28373688. Pubmed Central PMCID: 5628107.

65. Ma X, Xu S. TNF inhibitor therapy for rheumatoid arthritis. Biomedical reports. 2013 Mar;1(2):177-84. PubMed PMID: 24648915. Pubmed Central PMCID: 3956207.

66. van der Heijde DM, van 't Hof MA, van Riel PL, Theunisse LA, Lubberts EW, van Leeuwen MA, et al. Judging disease activity in clinical practice in rheumatoid arthritis: first step in the development of a disease activity score. Annals of the rheumatic diseases. 1990 Nov;49(11):916-20. PubMed PMID: 2256738. Pubmed Central PMCID: 1004262.

67. Tak PP, Bresnihan B. The pathogenesis and prevention of joint damage in rheumatoid arthritis: advances from synovial biopsy and tissue analysis. Arthritis and rheumatism. 2000 Dec;43(12):2619-33. PubMed PMID: 11145019.

68. Hamilton JA, Tak PP. The dynamics of macrophage lineage populations in inflammatory and autoimmune diseases. Arthritis and rheumatism. 2009 May;60(5):1210-21. PubMed PMID: 19404968.

69. Fujii K, Tsuji M, Tajima M. Rheumatoid arthritis: a synovial disease? Annals of the rheumatic diseases. 1999 Dec;58(12):727-30. PubMed PMID: 10577956. Pubmed Central PMCID: 1752821.

70. Behniafard N, Gharagozlou M, Farhadi E, Khaledi M, Sotoudeh S, Darabi B, et al. TNF-alpha single nucleotide polymorphisms in atopic dermatitis. European cytokine network. 2012 Oct-Dec;23(4):1635. PubMed PMID: 23328497.

71. Sumimoto S, Kawai M, Kasajima Y, Hamamoto T. Increased plasma tumour necrosis factor-alpha concentration in atopic dermatitis. Archives of disease in childhood. 1992 Mar;67(3):277-9. PubMed PMID: 1575548. Pubmed Central PMCID: 1793658.

72. Nie X, Kitaoka S, Tanaka K, Segi-Nishida E, Imoto Y, Ogawa A, et al. The Innate Immune Receptors TLR2/4 Mediate Repeated Social Defeat Stress-Induced Social Avoidance through Prefrontal Microglial Activation. Neuron. 2018 Aug 8;99(3):464-79 e7. PubMed PMID: 30033154.

\section{Figures}



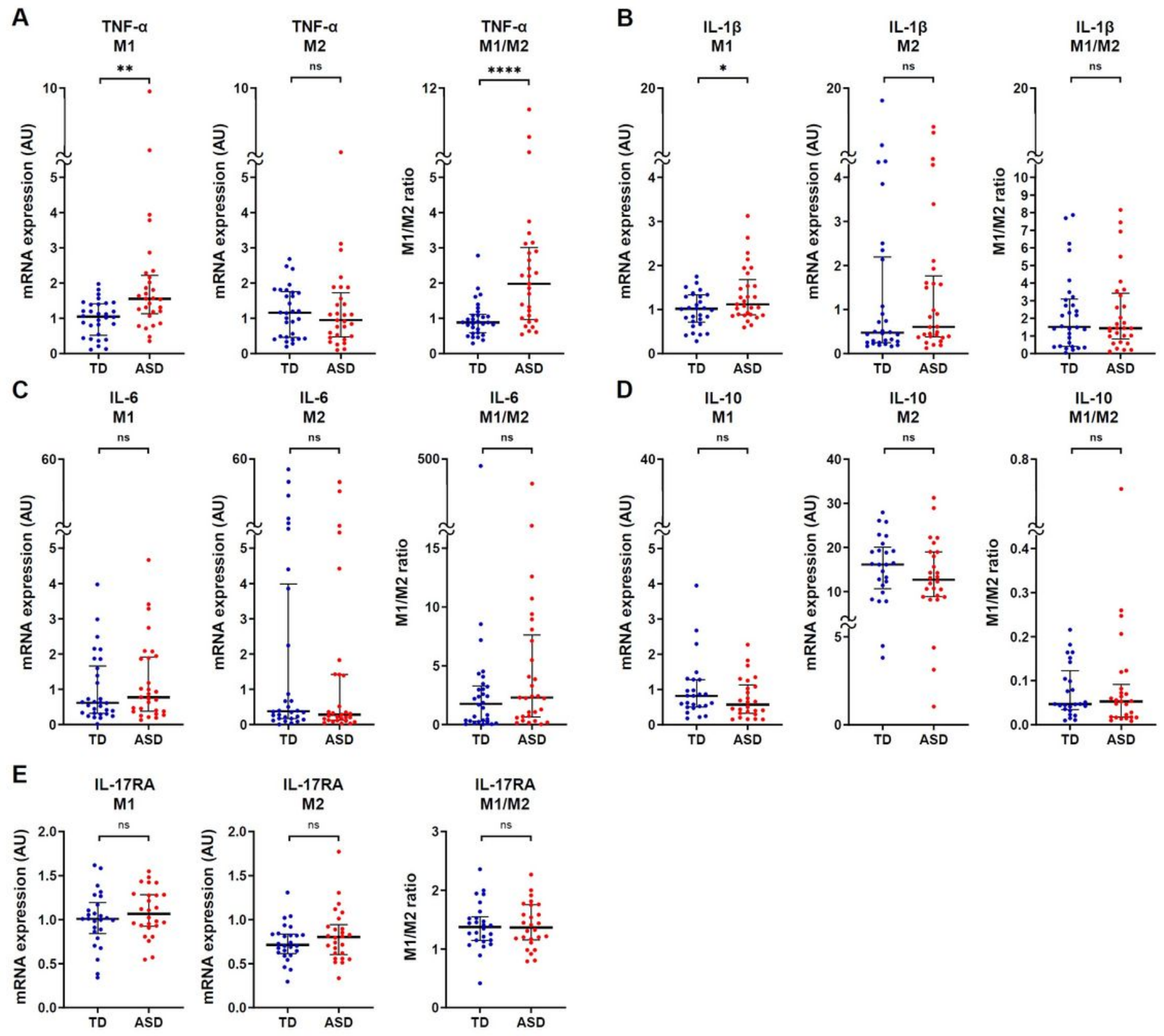

\section{Figure 1}

Cytokine and cytokine-related mRNA expression levels in M1 and M2 macrophages of ASD patients and TD individuals. (A) TNF-a mRNA expression in M1 macrophages was higher in the ASD group than in TD (ASD, median $=1.557 ;$ TD, median $=1.049, \mathrm{U}=224, \mathrm{p}=0.0011$ ), and the TNF- $\mathrm{a}$ mRNA expression ratio of M1/M2 macrophages was markedly higher in ASD than in TD (ASD, median $=1.977 ;$ TD, median $=0.885$, $U=180, p<0.0001$ ) (ASD, $n=29 ; T D, n=30$ ). (B) IL-1 $\beta$ mRNA expression in M1 macrophages is higher in ASD than in TD (ASD, median = 1.120; TD, median $=1.018, \mathrm{U}=305, \mathrm{p}=0.049)(\mathrm{ASD}, \mathrm{n}=29 ; \mathrm{TD}, \mathrm{n}=30)$.

(C) No significant difference was observed in the IL-6 mRNA expression levels in M1 and M2 macrophages between the two groups (ASD, $n=29 ; T D, n=30$ ). (D) No significant difference was observed in the IL-10 mRNA expression in M1 and M2 macrophages between the two groups (ASD, $n=$ $26 ; T D, n=25$ ). (E) No significant difference was observed in the IL-17RA mRNA expression in M1 and M2 
macrophages between ASD and TD subjects (ASD, $n=26 ; T D, n=26$ ). $P$ values were determined using

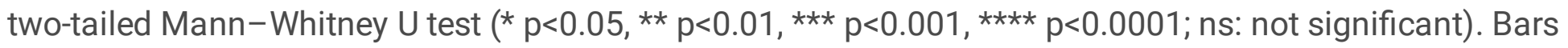
represent the median and interquartile range. ASD: autism spectrum disorder; TD: typically developed; M1: M1 macrophage; M2: M2 macrophage; M1/M2: mRNA expression ratio of M1/M2 macrophages.
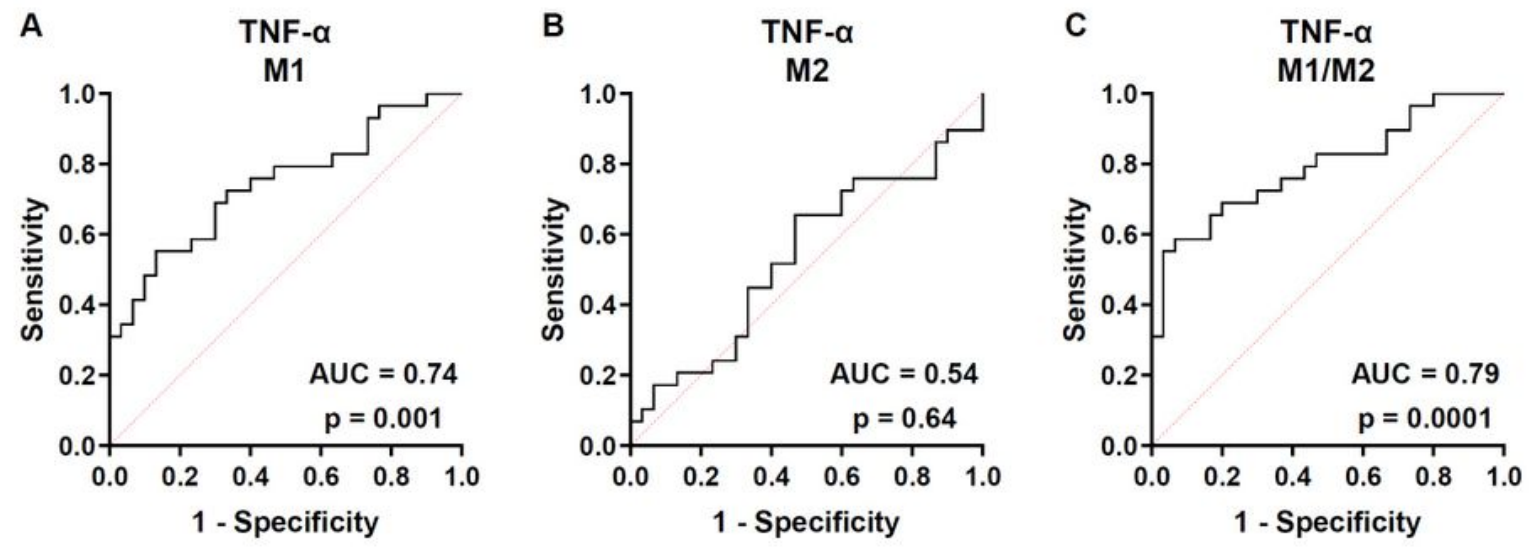

D
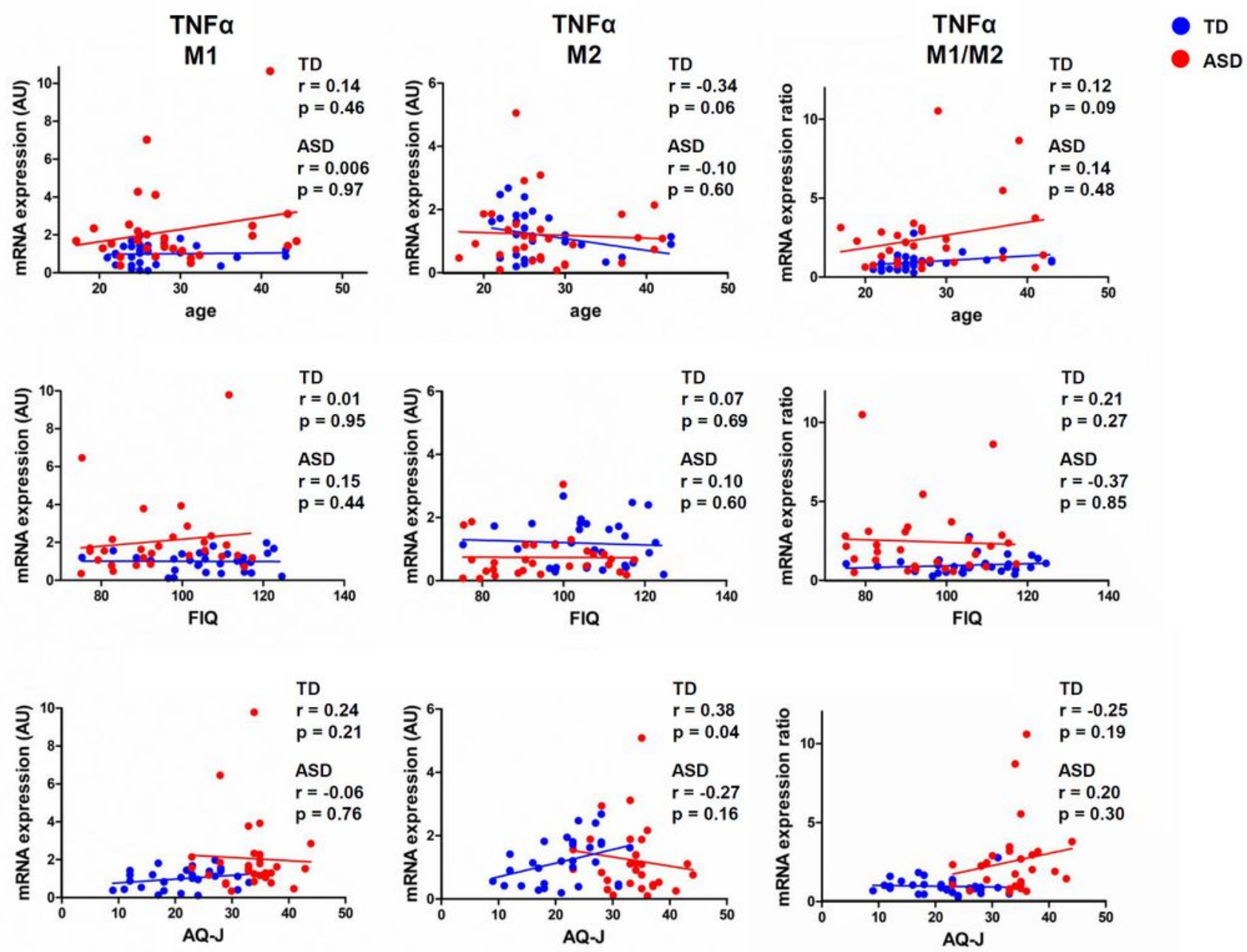

Figure 2 
ROC curves of the TNF-a mRNA expression levels in M1 and M2 macrophages, and correlations of TNF-a mRNA expression with age, FIQ, and AQ-J score in ASD and TD (A) ROC curve of the TNF-a mRNA expression in $\mathrm{M} 1$ macrophages. AUC with $95 \% \mathrm{Cl}$ was calculated (AUC $=0.74,95 \% \mathrm{Cl}: 0.62-0.87, \mathrm{p}=$ 0.001). (B) ROC curve of the TNF-a levels in M2 macrophages. AUC with $95 \% \mathrm{Cl}$ was calculated (AUC = $0.54,95 \% \mathrm{Cl}: 0.39-0.69, \mathrm{p}=0.64$ ). (C) ROC curve of the TNF-a levels in the ratio of M1/M2. AUC with $95 \%$ $\mathrm{Cl}$ was calculated (AUC $=0.79,95 \% \mathrm{Cl}: 0.68-0.91, \mathrm{p}=0.0001$ ). (D) TNF-a mRNA expression in either M1 or M2 macrophages did not correlate with age, FIQ, or severity of ASD symptoms (AQ-J score) in ASD and TD except for the correlation of TNF-a mRNA expression in M2 macrophages with AQ-J score. TNF- $a$ mRNA expression ratio of M1/M2 macrophages did not correlate with either age, FIQ, or AQ-J score in ASD and TD (ASD, $n=29 ;$ TD, $n=30$ ). P-values were determined using Spearman's rank coefficient. ROC: receiver operating characteristic; AUC: area under the curve; Cl: confidence interval; TD: typically developed; ASD: autism spectrum disorder; M1: M1 macrophage; M2: M2 macrophage; M1/M2: mRNA expression ratio of M1/M2 macrophages; FIQ: full intelligence quotient; AQ-J: Autism Quotient-Japanese version

A

TNF- $\alpha$ Monocyte
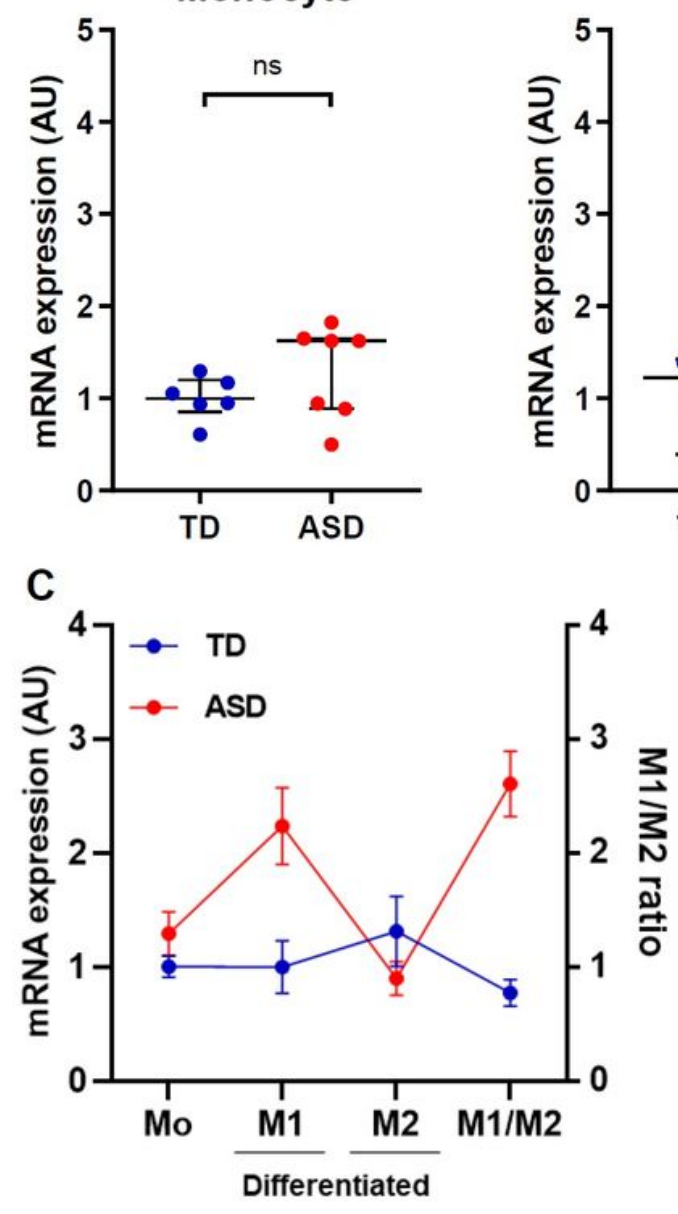

TNF- $\alpha$

M1

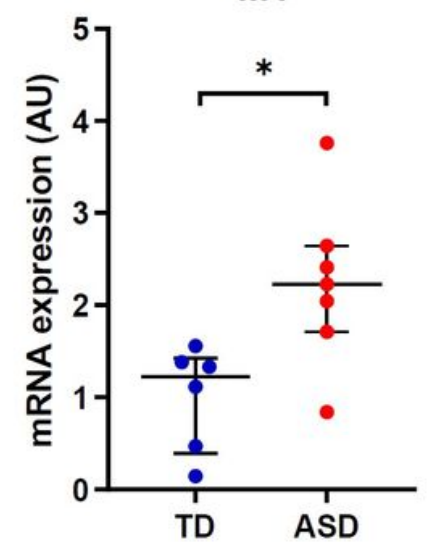

TNF- $\alpha$

M2

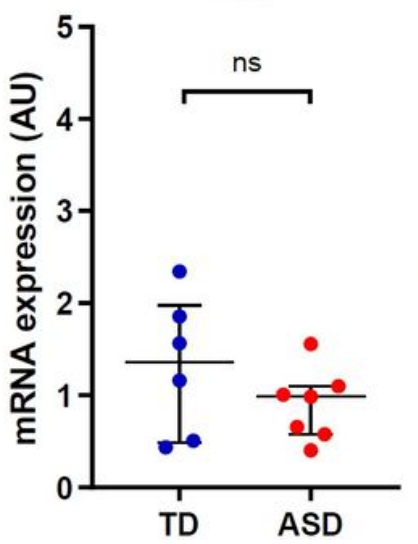

TNF- $\alpha$ M1/M2

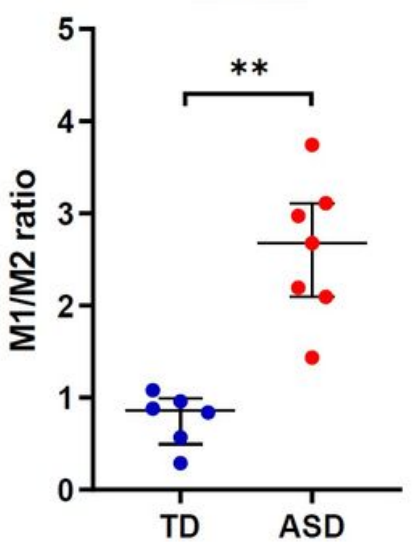

Figure 3 
TNF-a mRNA expression in monocytes between ASD and TD (A) No significant difference was observed in the TNF-a mRNA expression in monocytes between ASD and TD subjects (ASD, median $=1.621$; TD, media $=1.000, U=15, p=0.45)(n=6 ; A S D, n=7) .(B)$ In the same individuals from whom monocytes were collected, TNF-a mRNA expression in M1 macrophages, but not in M2 macrophages, and the ratio of M1/M2 macrophages were significantly higher in ASD than TD (M1: ASD, median $=2.229 ;$ TD, median = $1.225, \mathrm{U}=4, \mathrm{p}<0.014)(\mathrm{M} 2:$ ASD, median $=0.987 ; \mathrm{TD}$, media $=1.362, \mathrm{U}=13, \mathrm{p}=0.29)(\mathrm{M} 1 / \mathrm{M} 2:$ : ASD, median $=2.677 ;$ TD, median $=0.860, U=0, p=0.001)(n=6 ; A S D, n=7) .(C)$ Transition of TNF-a mRNA expression levels between monocytes and $M 1$ and $M 2$ macrophages, and the M1/M2 ratio. P-values were determined using two-tailed Mann-Whitney $U$ test ( ${ }^{*} p<0.05,{ }^{* *} p<0.01$; ns: not significant). Bars represent the median and interquartile range. TD: typically developed; ASD: autism spectrum disorder; M1: M1 macrophage; M2: M2 macrophage; M1/M2: mRNA expression ratio of M1/M2 macrophages; Mo: monocyte

\section{Supplementary Files}

This is a list of supplementary files associated with this preprint. Click to download.

- Suppl.Table1.tif

- Suppl.Table1.tif

- Suppl.Fig.1rev.tif

- Suppl.Fig.1rev.tif

- Suppl.Fig.2rev.tif

- Suppl.Fig.2rev.tif

- Suppl.Fig.3rev.tif

- Suppl.Fig.3rev.tif 